\title{
ATM systems and Wind Farms
}

\author{
Andrej Novak \\ University of Žilina \\ Slovakia
}

\section{Introduction}

Air safety includes all the rules and processes that enable commercial and cargo aeroplanes to fly safely across the European Union. It includes rules on aircraft construction and use, infrastructure safety, data management and analysis, flying operations, and cargo.

Air safety management aims to spot potential accidents and incidents before they occur. It is not the same as air security, which seeks to prevent voluntary illegal and harmful acts in the field of aviation. The wind is an increasingly important source of energy, but negative impact on air transport is in area of Air Traffic Services. Communication Navigation and Surveillance systems are endangered with big wind farms. Primary problem is in radar system and is detailed described in my text.

The potential impacts of wind farms on air traffic management include the cumulative effects on the Slovak republic airspace management and surveillance infrastructure and affect the following systems:

- Primary Radar,

- Secondary Surveillance Radar (SSR),

- Microwave links associated with a) and b),

- Navigation Aids

Background information on how these systems work and are used, together with the effects of wind turbines and mitigation techniques, is at next chapter. The remainder of this section concentrates on how the systems above can be affected by wind turbines and identifies, where known, mitigating measures that can be taken from a developer's perspective. However, many of the precise effects of wind turbines on these systems are not yet fully understood and the guidance issued in this section must therefore be considered as interim, based on the best knowledge currently available.

It should be borne in mind that it is not the effect that wind turbines have on technical systems in themselves that is important but the end effect that is caused to flight safetycritical air traffic management operations. Hence, if pragmatic solutions can be found (for example, by replacing the service provided by an affected SSR with a suitably located 
replacement SSR), these may offer a way forward. On the other hand, if on aerodrome approach radar must be situated in one particular location in order to ensure safety of departing and arriving aircraft, any proposal for wind turbines that will cause detrimental effects to the radar is unlikely to be acceptable.

\subsection{Radar Introduction}

There are two types of radar used for air traffic control and air defence control and surveillance: Primary Surveillance Radar (PSR) and Secondary Surveillance Radar (SSR).

Primary radar operates by radiating electromagnetic energy and detecting the presence and character of the echo returned from reflecting objects. Comparison of the returned signal with that transmitted yields information about the target, such as location, size and whether it is in motion relative to the radar.

Primary radar cannot differentiate between types of object; its energy will bounce off any reflective surface in its path. Moreover, air traffic control primary radar has no means of determining the height of an object, whereas modern air defence radars do possess this capability, using electronic beam control techniques.

For SSR, the ground station emits 'interrogation' pulses of radio frequency (RF) energy via the directional beam of a rotating antenna system. When the antenna beam is pointing in the direction of an aircraft, airborne equipment, known as a transponder, transmits a reply to the interrogation (Gabriel \& Hill, 2004). The reply is detected by the ground station and processed by a plot extractor.

The plot extractor measures the range and bearing of the aircraft and decodes the aircraft replies to determine the aircraft's flight level and identity (Mode C operation). In the Slovak Republic, all aircraft flying in controlled airspace must carry a SSR transponder. Some light aircraft do not, and aircraft that do carry them may not have them switched on, in which case they will not be visible to SSR. Most ATC units are equipped with both primary and SSR, but, increasingly, radar services are provided using SSR only.

From 2008 onwards, a new type of SSR called 'Mode S' will begin to be introduced in the SR airspace. Mode S is a development of classical SSR that overcomes many of the current limitations of the SSR system. It is proposed, subject to formal consultation, to introduce Mode S initially in 2008 with a second phase of regulatory changes in 2008. In addition, it is proposed that the requirements for the carriage and operation of transponders will be significantly extended in conjunction with the Mode S plans for 2009/2010.

\section{Basic Radar Functions}

Radar performs two functions for air traffic control:

a) Aerodrome surveillance radar allows air traffic controllers to provide air traffic services to aircraft in the vicinity of an airport. This service may include vectoring aircraft to land, providing a radar service to departing aircraft or providing a service to aircraft either transiting through the area or in the airfield circuit. 
b) En route (or area) radars are used to provide services to traffic in transit. This includes commercial airliners and military traffic. Area radars have a longer range than aerodrome radars, particularly at high altitudes.
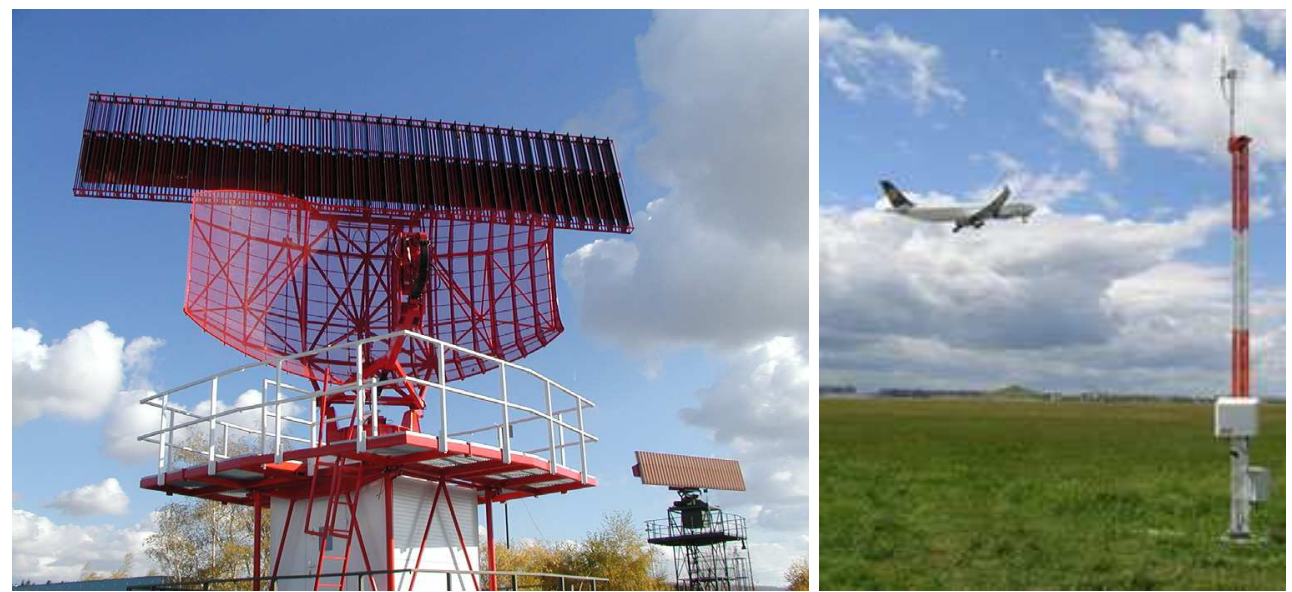

Fig. 1. Primary and secondary surveillance radar (picture source: author)

\subsection{Air Defence}

Air Defence radars are used in two ways. On the one hand, they perform a similar function to their ATC counterparts, in that they are used by air defence controllers to provide control services to military (usually air defence) traffic. However, they are also used to monitor all air traffic activity within the Slovak Republic and its approaches in order that a Recognised Air.

Recognised Air Picture can be produced, with the aim of preserving the integrity of the SR airspace through air policing. The Recognised Air Picture is produced by allocating Track Identities to each radar return (or "plot") of interest. Often, a radar plot can fade from a radar display for a period of time due to a number of factors, but the Track Identity will remain, indicating that the associated plot is still actually present (CAP 670, CAP 764).

\subsection{Meteorological Radars}

Meteorological Office weather radars use electromagnetic energy to monitor weather conditions (predominantly cloud and precipitation) at low altitudes, in order to assist weather forecasting. Wind profiling radars are used to measure wind speed at different altitudes.

There are 2 weather radar stations in the Slovakia ( 1 in Kojsova Hola and 1 in Maly Javornik) and they are used for monitoring weather conditions to assist in forecasting. A map of Meteorological Office radar sites is at Fig. 2. In simple terms, two types of radar are used:

- weather radar and

- $\quad$ wind profiling radar. 


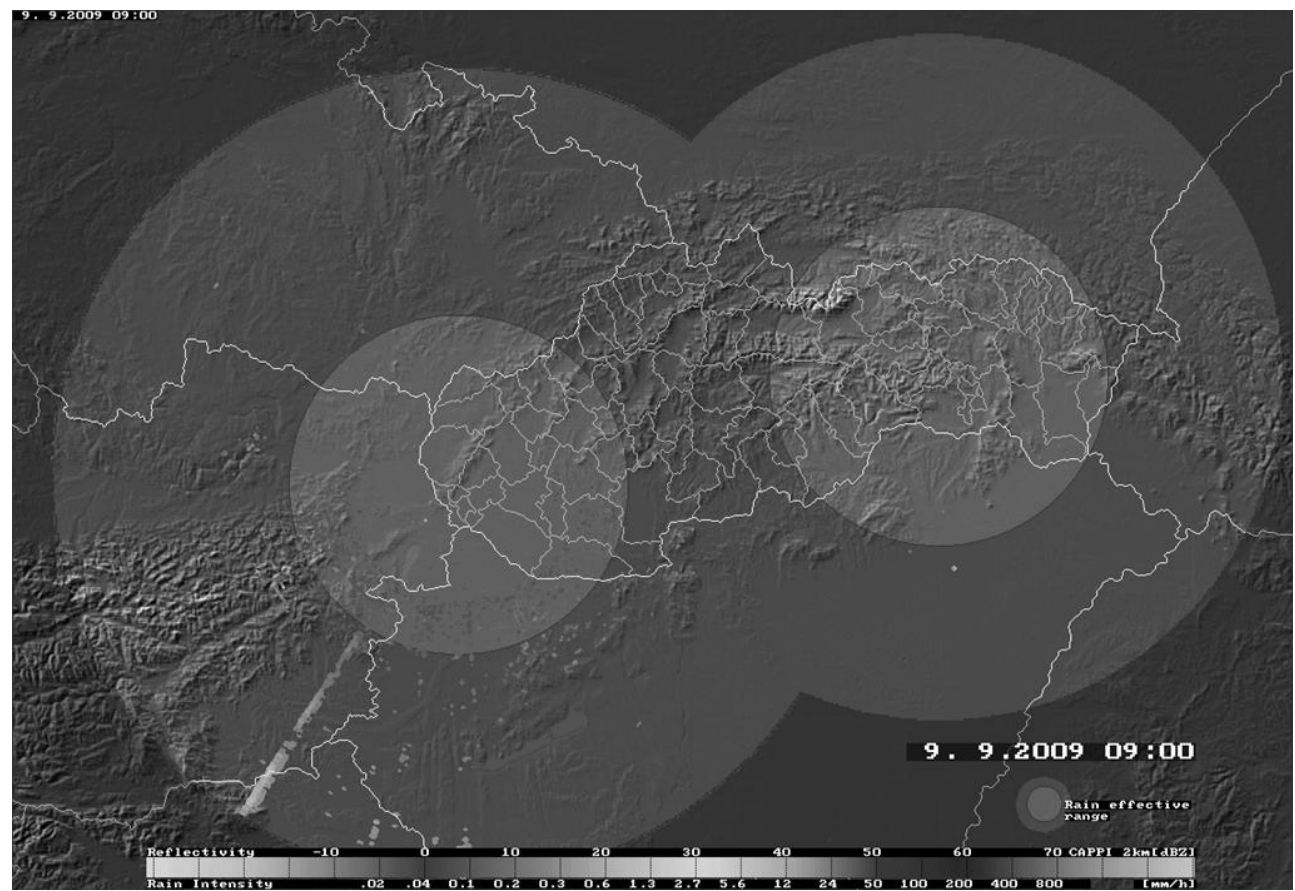

Fig. 2. Weather radar on Kojsova hola and Maly Javornik (picture source: author)

Weather radar is designed to look at a thin layer of the atmosphere, as close to the ground as possible, for accurate forecasting. For this reason, sites are situated on high ground and look out at a narrow band of airspace between 0 and $1^{\circ}$ planning wind farms in close proximity to Meteorological Office wind profiling radars. As with all other issues, the key is to engage in dialogue with the Meteorological Office as early as possible if it is anticipated that there may be a conflict of elevation. Subsequently, there is potential for interference from wind turbines.

The easiest way to avoid disruption to weather radar is to ensure that the maximum height of the turbines (above mean sea level) is below the height of the radar. This will ensure that there is no interference. In addition, if terrain features lying between the turbine and the radar mask the turbines they will have no impact on the operation of the radar. Put simply, weather radar may still be able to operate with a few wind turbines within its line of sight, dependent upon range and other factors.

Accurate weather forecasting and reporting is highly important to aviation safety. One of the most important effects for aircraft is "wind shear", where the winds at different altitudes may vary greatly in both direction and speed. Wind profiling radars are susceptible to spurious reflections and, for this reason, developers should avoid 


\subsection{Airborne Weather Radar}

Airborne Weather Radar provides the pilot with a local (ahead only) weather picture in the cockpit and allows him to identify and avoid specific, undesirable weather formations. A maximum range of $180 \mathrm{NM}$ is common although the commonly used range (as selected by pilots) would normally be in the 30 to $80 \mathrm{NM}$ range.

\section{The Nature of the Impacts of Wind Turbines}

\section{Masking}

This is the main anticipated effect on air defence surveillance radars. Such radars work at high radio frequencies and therefore depend on a clear "line of sight" to the target object for successful detection. It follows that any geographical feature or structure which lies between the radar and the target will cause a shadowing or masking effect; indeed this phenomenon is readily exploited by military aircraft wishing to avoid detection. It is possible that, depending on their size, wind turbines may cause shadowing effects. Such effects may be expected to vary, depending upon the turbine dimensions, the type of transmitting radar and the aspect of the turbine relative to it.

The Meteorological Office is also concerned with the effect of masking on their sensors. Meteorological Office radars look at a relatively narrow altitude band, as near to the earth's surface as possible. Due to the sensitivity of the radars, wind turbines, if they are poorly sited, have the potential to significantly reduce weather radar performance.

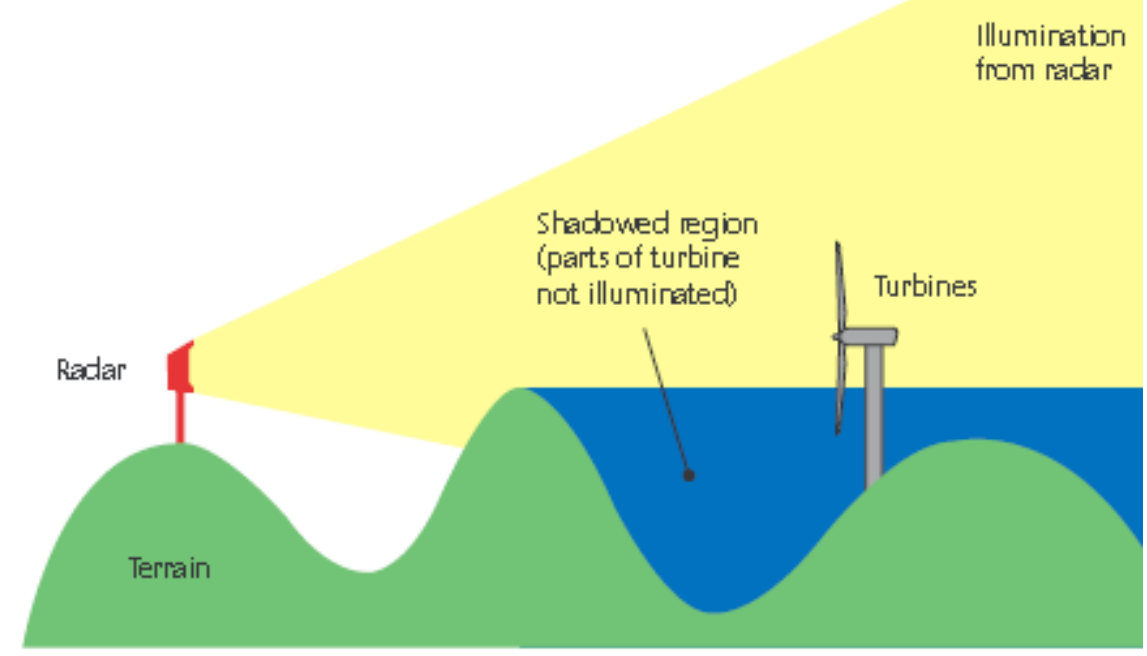

Fig. 3. General geometry of the problem - terrain shadowing (source: Greving, 2001)

Radar returns may be received from any radar-reflective surface. In certain geographical areas, or under particular meteorological conditions, radar performance may be adversely 
affected by unwanted returns, which may mask those of interest. Such unwanted returns are known as radar clutter. Clutter is displayed to a controller as "interference" and is primarily to air defence in Slovakia and aerodrome radar operators, because it occurs more often at lower altitudes (Lewis, 2001).

For an aerodrome radar operator, a wind turbine or turbines in the vicinity of his airfield can present operational problems. If the turbine generates a return on his radar screen and the controller recognises it as such, he may choose to ignore it. However, such unwanted returns may obscure others that genuinely represent aircraft, thereby creating a potential hazard to flight safety. This may be of particular concern in poor weather.

A structure which permanently paints on the radar in the same position is preferable to one that only presents an intermittent return. This is because an intermittent return is more likely to represent a manoeuvring or unknown aircraft, obliging the controller to act accordingly. With this in mind, it is possible that aviators and radar operators could work safely with one or perhaps two turbines in the vicinity of an aerodrome. Of greater concern is the prospect of a proliferation of turbines, which could potentially saturate an airfield radar picture, making safe flying operations difficult to guarantee.

Several turbines in close proximity to each other, painting on radar, can present particular difficulties for long-range air surveillance radars. A rotating wind turbine is likely to appear on a radar display intermittently (studies suggest a working figure to be one paint, every six sweeps).

Multiple turbines, in proximity to each other, will present several returns during every radar sweep, causing a 'twinkling' effect. As these will appear at slightly different points in space, the radar system may interpret them as being one or more moving objects and a surveillance radar will then initiate a 'track' on the returns. This can confuse the system and may eventually overload it with too many tracks. Measures can be taken to mitigate this problem and they are amplified, but these too have their drawbacks.

The radar modelling study mentioned in Knill, 2001 includes some field measurements which will be used to validate the model. Figure 4 shows some data from these trials. It shows the Doppler signal against time recorded by a radar array from a single $1.5 \mathrm{MW}$ turbine. The turbine rotor was at an angle of $30^{\circ}$ to the radar direction, with a rotor speed of 20.3RPM. 


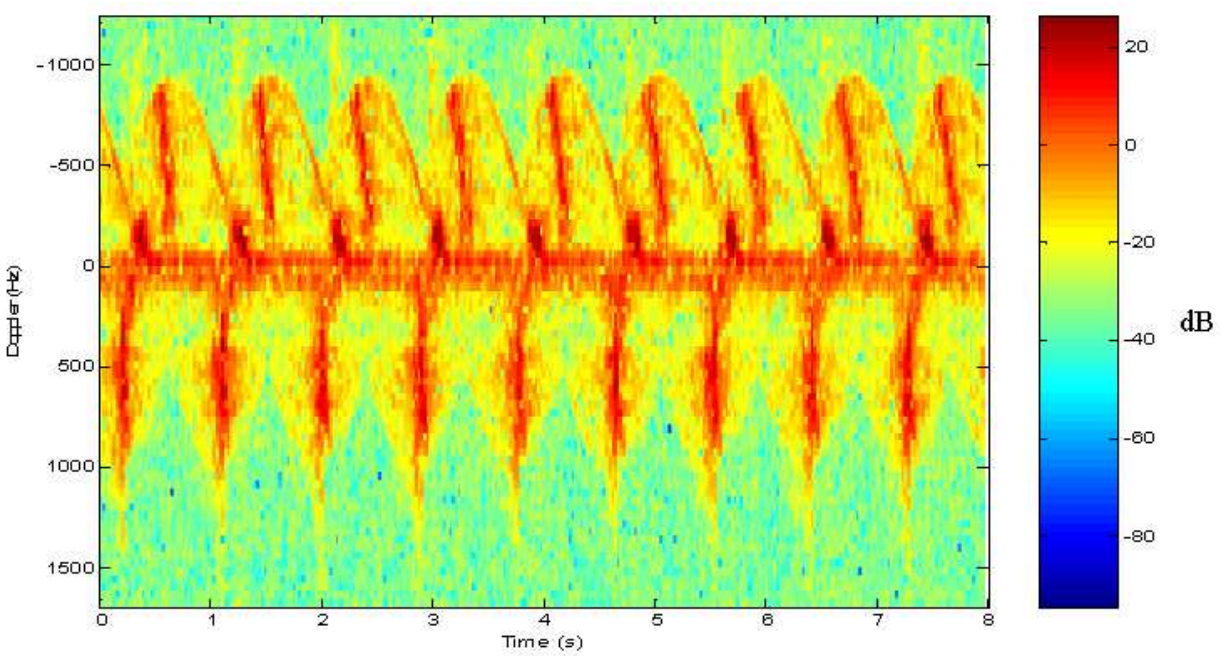

Fig. 4. Doppler radar signal from a single wind turbine

\section{Radars Errors}

It is important to clarify some of the common technical terms used throughout this document. Every effort has been made to use these terms consistently where their relevance has been discussed. The list comprises terms which are either felt to be sufficiently technical to warrant explanation, or it was felt that their use in the open literature was often ambiguous or confusing. Full technical treatments of these terms can be found in (Skolnik, 1962) and (Knott et al, 1993).

\section{Diffraction}

Diffraction is a special type of reflection, where energy is scattered by a discontinuity (e.g. the sharp edge of a wind turbine blade). Smooth objects will also diffract if the curvature is tight enough (compared to the wavelength of the EM wave). When an incoming EM wave hits an edge, energy is diffracted in all directions.

\section{Multi-path}

Multi-path refers to an EM wave travelling from one point to another via some intermediate object where it suffers a reflection. In this context, multi-path refers to a transmitted signal being reflected from a wind turbine before it reaches the receiver.

\section{Reflection}

This is a general "catch-all" term describing the fact that when an EM wave hits an object, it reflects/scatters energy in a number of directions. Radar reflections should be considered to be synonymous with "radar echoes" and "target scattering".

\section{Refraction}

Refraction is a phenomenon where the direction of a signal (an EM wave) changes as it passes through a medium whose refractive index (related to the density of the medium) changes. The 
change can be abrupt (e.g. the bending of light entering a glass of water) or gradual (e.g. the bending of radio waves as they travel through the atmosphere). The amount of bending also depends on the frequency of the wave - this is why prisms split "white light" into a rainbow because the different wavelengths are refracted by different amounts.

\section{Shadowing}

A shadow is a region of space where the strength of an electric field is reduced behind an object, compared to what the signal strength would have been without the object.

\section{Signal / EM wave}

All of the ATC systems in this report transfer information using RF signals. The "signal" is an electromagnetic (EM) wave which propagates at the speed of light, $c$. The frequency of an EM wave is inversely proportional to its wavelength, $\lambda$, by the equation $c=f \lambda$. The strength of an EM wave is measured in terms of its electric field-strength. The power carried by the wave is proportional to the square of the electric field-strength.

The relationship between the underlying physical mechanisms (causes) and the observed ATC impacts is illustrated in Figure 5 and Figure 6. Figure 6 considers generic ATC impacts while Figure 5 only considers those which are specific to PSR systems. In both figures it is assumed that the radar receiver has a threshold of $P_{\text {thresh }}$ - i.e. only signals with a power greater or equal to $P_{\text {thresh }}$ will be detected. The cause of each impact is related simply to the system's measured quantities - the time or arrival, the direction of arrival and the strength of the signal.

\begin{tabular}{|l|} 
Direct signal arrives at: \\
Time $\mathrm{T}_{1}$ \\
Bearing $\mathrm{B}_{1}$ \\
Power $\mathrm{P}_{1}$
\end{tabular}

Fig. 5. Illustration of the technical cause of PSR-specific ATC impacts 


\begin{tabular}{|c|c|}
\hline $\begin{array}{l}\text { Direct signal arrives at: } \\
\text { Time } \mathrm{T}_{1} \\
\text { Bearing } \mathrm{B}_{1} \\
\text { Power } \mathrm{P}_{1}\end{array}$ & 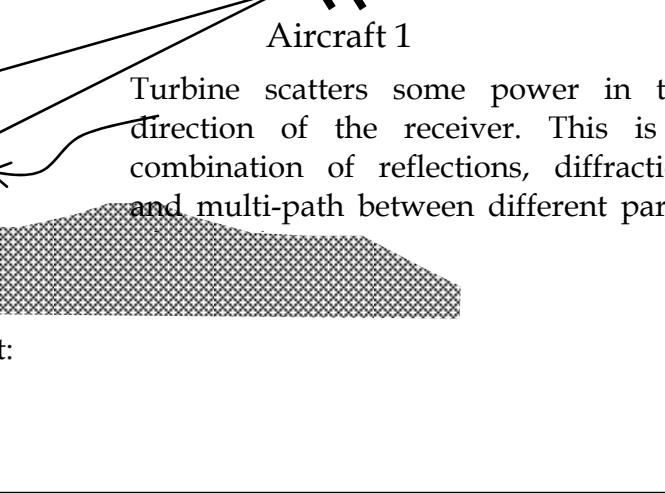 \\
\hline ATC Impact & Technical cause \\
\hline $\begin{array}{l}\text { Signal loss due to shadowing } \\
\text { (fading) }\end{array}$ & $\begin{array}{l}P_{1} \& P_{2} \text { combine with net effect of reducing P1. } \\
T_{1} \& T_{2} \text { are very close }\end{array}$ \\
\hline Signal corruption & $\mathrm{P}_{1} \& \mathrm{P}_{2}$ have similar strengths \\
\hline Receiver saturation & $\mathrm{P}_{2}$ too large and saturates the receiver \\
\hline Error in bearing & $\mathrm{B}_{1}$ and $\mathrm{B}_{2}$ different, $\mathrm{P}_{1}$ and $\mathrm{P}_{2}$ \\
\hline Errors in height & $\mathrm{P}_{2}$ too large and affects 3D PSR operation \\
\hline Ghost / False target & $\mathrm{P}_{2}>\mathrm{P}_{\text {thresh }}$ and $\mathrm{T}_{2}$ separable from $\mathrm{T}_{1}$ \\
\hline
\end{tabular}

Fig. 6. Illustration of the technical cause of ATC impacts for non-PSR systems

\section{Potential Mitigating Measures}

\subsection{Introduction}

Wind turbines have a variety of impacts on ATC capability. Firstly, wind turbines present a physical obstruction which can modify or reduce a system's functionality. In this respect wind turbines are no different from any other object (e.g. a building, structure or terrain). Secondly, wind turbines have moving parts; their dynamic nature is the main reason that necessitates the development of specialised assessment methodologies.

A wind turbines motion has three distinct aspects worth noting here. These have different implications for the impact on ATC systems.

1. The reflections are time-varying. Because a wind turbine rotates on one or more axis, the way in which it will interfere with an EM system will vary. This means that impacts are more difficult to predict and more difficult to avoid. For instance, the strength of radar reflections from large wind turbines will vary from second to second (as the blades rotate). There may also be longer time-scale changes in the nature of the reflections, as the nacelle axis changes direction to face into the wind.

2. Doppler content. When EM waves reflect from a moving object, the frequency of the reflected energy is changed slightly as a result of the radial motion. This is analogous with the change in pitch of an ambulance siren as it passes - the change in pitch is caused by the change in wavelength of the reflected waves. Due to the 
fact that the velocity of EM waves remains constant, the change in wavelength results in a small change in frequency. The shift in frequency is referred to as the Doppler shift. The Doppler content is used to remove echoes from stationary objects such as buildings and terrain. This does not work for wind turbines because of their moving parts.

3. Magnitude of reflections. The reflection magnitude of the moving parts of a typical HAWT, namely the rotor, can be very large. Although the magnitude can vary over several orders of magnitude, at some point in the rotation of the blades RCS levels of up to $40 \mathrm{dBsm}(10,000$ square metres) are predicted and have been measured. Signals of this size can easily be detected by radar even when close to the ground where radar coverage may not be good. This makes it difficult to "shield" wind turbines from nearby radar sites. Also if the turbines are well illuminated by the radar, detecting small aircraft (circa $1 \mathrm{~m} 2 \mathrm{RCS}$ ) close to the turbines, may be difficult due to limitations within the radar receiver or impacts to the radar clutter map.

Before progressing it is worthwhile to illustrate the second point further. Because the blades of a conventional HAWT have a spread of speeds (the tip travels faster than a point further down the blade) there is a spread of Doppler shifts in radar echoes. This is illustrated in Figure 7 .

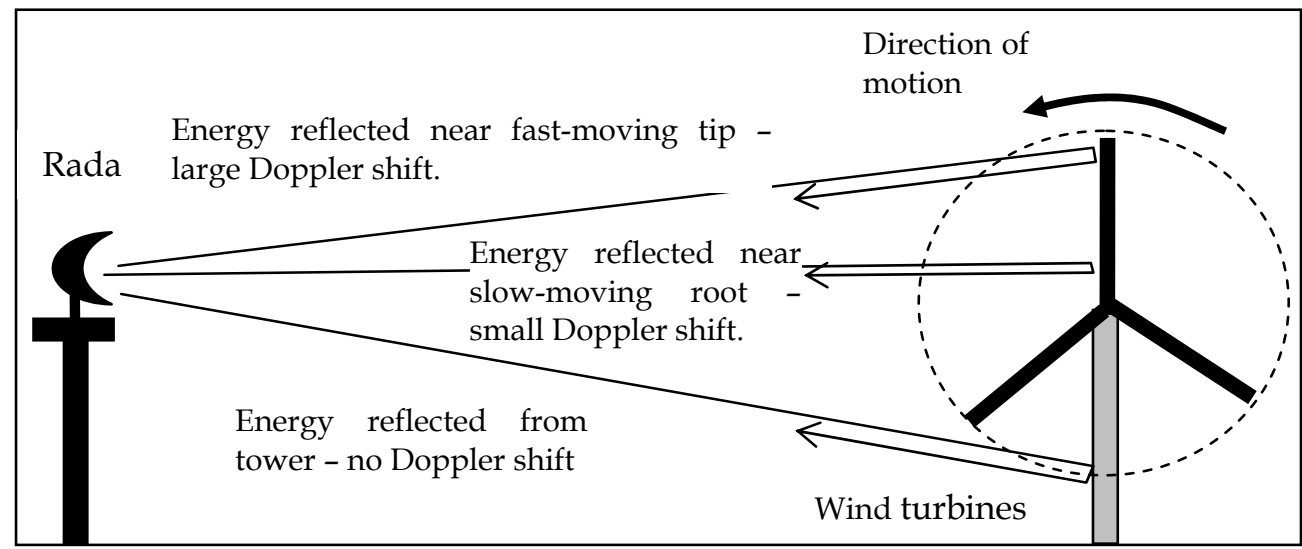

Fig. 7. Illustration of Doppler spread from a wind turbines

The Doppler content of targets is used by primary radars to discriminate between genuine targets (aircraft) and clutter (buildings, vehicles, trees, wind turbines, etc.). Moving Target (MTI) and Moving Target Detection (MTD) filters are employed to remove echoes from slow moving or stationary objects because these are unlikely to be aircraft. For example, a basic MTI filter will remove returns from stationary buildings and these returns will not be presented to the ATC display. Equally, a basic MTI filter will remove echoes from the slowmoving blade roots and the stationary tower on a horizontal axis wind turbines. More detailed discussions of Doppler from moving targets and MTI/MTD processing can be found in (Knil, 2002). 
As the state-of-the-art of wind turbine design evolves it is possible that the nature of the Doppler content in wind turbine echoes will change, either increasing or diminishing the severity of the impacts on ATC systems. Although this possibility cannot be discounted, two points are made:

1. Maximum tip-speeds are fairly constant over all current designs, irrespective of turbine size. For example, with horizontal axis wind turbines, as the rotor diameter increases, the revolution speed drops. Small wind turbines typically have a higher rate of rotation. There is no evidence those maximum tip-speeds and hence the spread of Doppler content in wind turbine echoes will change substantially over the next ten years. There is of course a strong correlation between the size of the turbine and the magnitude of the echoes.

2. Constraints such as mechanical integrity and noise pollution mean maximum tipspeeds are unlikely to increase dramatically above existing values.

\subsection{Technical measures}

\section{Moving Target Indicator Processing}

Objects that are moving cause a shift in the frequency of the returned EM energy to the radar receiver; this is known as Doppler shift. Moving Target Indicator (MTI) processing removes from the display any returned pulses which indicate no movement or are within a specified range of Doppler shift. This removes unnecessary clutter, eliminates unwanted moving targets (such as road traffic) and makes moving targets above a certain velocity more visible.

Rotating wind turbine blades can impart Doppler shift to EM energy reflecting off the blades. Depending on the MTI thresholds set in the radar processor, this may be displayed as a moving target. Changes in wind direction at the turbine, the position of the blade in its rotation, the blade pitch, plus other factors, may cause the amount of energy returned to the radar on different sweeps to vary. At single turbine sites, a radar return will be repeatedly displayed in the same position and MTI processing can be deployed. However, multipleturbine sites cause a different effect and MTI processing is much more difficult. On one return, blades from one (or more) turbine(s) may paint on the radar; on the next sweep, the blades of a different turbine may paint. This can create the appearance of radar returns moving around within the area of the wind farm.

On both aerodrome and air defence radar this can appear (depending on the type of radar and the processing thresholds in effect) as unknown aircraft manoeuvring unpredictably. On air defence radars such as those used in the air defence of the Slovak Republic, the overall system may well interpret the activity as an aircraft and automatically start tracking the activity.

\section{Filters}

It is technically possible with many types of radar to filter out returns from a given area to ensure they are not presented on operational displays. However, this is at the expense of detecting actual aircraft in the area concerned. In the case of radars that have the ability to discriminate returns in height, it may be possible to filter out only the affected height band. 
On other radars, all returns in the given area will be lost and, in effect, no overall operational benefit is gained.

\section{Non-Automatic Initiation}

A measure that can be taken within the Command and Control system to mitigate the effects of spurious radar returns is to establish what is known as a Non-Automatic Initiation (NAI) area. Within this area the system does not perform its normal function of automatic track association and correlation. This would prevent the system attempting to correlate the returns from a large number of turbines in order to form what it perceives to be aircraft tracks. Instead, a human operator monitors the affected area to manually detect genuine aircraft tracks. Whilst this technique can help to avoid the problems both for surveillance and control of spurious tracks, it can be manpower intensive and requires operator expertise. Furthermore, it cannot help to overcome the effect on safety of clutter. Indeed, the use of clutter filters and NAIs may be operationally mutually exclusive.

\subsection{Operational Measures}

The type of operations being conducted and the type of airspace within which a controller is operating are both relevant factors if radar clutter is being experienced.

\section{Controlled Airspace}

Within controlled airspace, flight is only possible if approved by an ATC authority. Therefore, controllers should know of all aircraft within that controlled airspace. In this case, if radar clutter is experienced, whether from a wind turbine or other obstacle, the controller may assume that the return is not from an unknown aircraft and will not need to take any action. (There are exceptions to this rule, which do not need to be explored here.)

\section{Outside Controlled Airspace}

Outside controlled airspace (in the Slovak Republic, categorised as 'Class G' airspace), clutter and unknown radar returns present more of a problem. In such airspace, the radar returns of aircraft are the primary means on which the separation of aircraft is based; therefore, clutter must be avoided, as it is the only way of ensuring separation from unknown aircraft.

What may occur is that radar clutter from a wind turbine may be interpreted as being a return from an aircraft; or the clutter may be obscuring a genuine radar return from an actual aircraft operating in the vicinity of that clutter.

There are two ways a controller can deal with this problem; the safest option is to simply avoid the area of clutter, usually by a range of 5 nautical miles. Naturally, this is not always possible. Alternatively, the controller may 'limit' his radar service, whereby he informs the aircraft receiving the service that, due to being in an area of clutter, the pilot may receive late or no warning of other aircraft.

Controllers use both methods but each presents its own problem. The cumulative effects of clutter make vectoring to avoid clutter harder and harder. Controllers may be able to cope with one or two areas of clutter, but there is a difficult judgement as to how much 
proliferation is acceptable. Alternatively, limiting the service is often a last resort, and to admit that clutter may well be obscuring returns from genuine aircraft is a clear indication that flight safety may be compromised.

The significance of unwanted radar returns from wind turbines will depend not only on what type of airspace they are in or underneath, but also on their proximity to traffic patterns and routes. Wind turbines on an extended centreline of a runway are more likely to present a significant problem to controllers at longer ranges due to aircraft lining up for approaches and on departure. Similarly, aerodromes have Standard Arrival Routes (STAR) and Standard Instrument Departure (SID) routes, which may also be considered problematic.

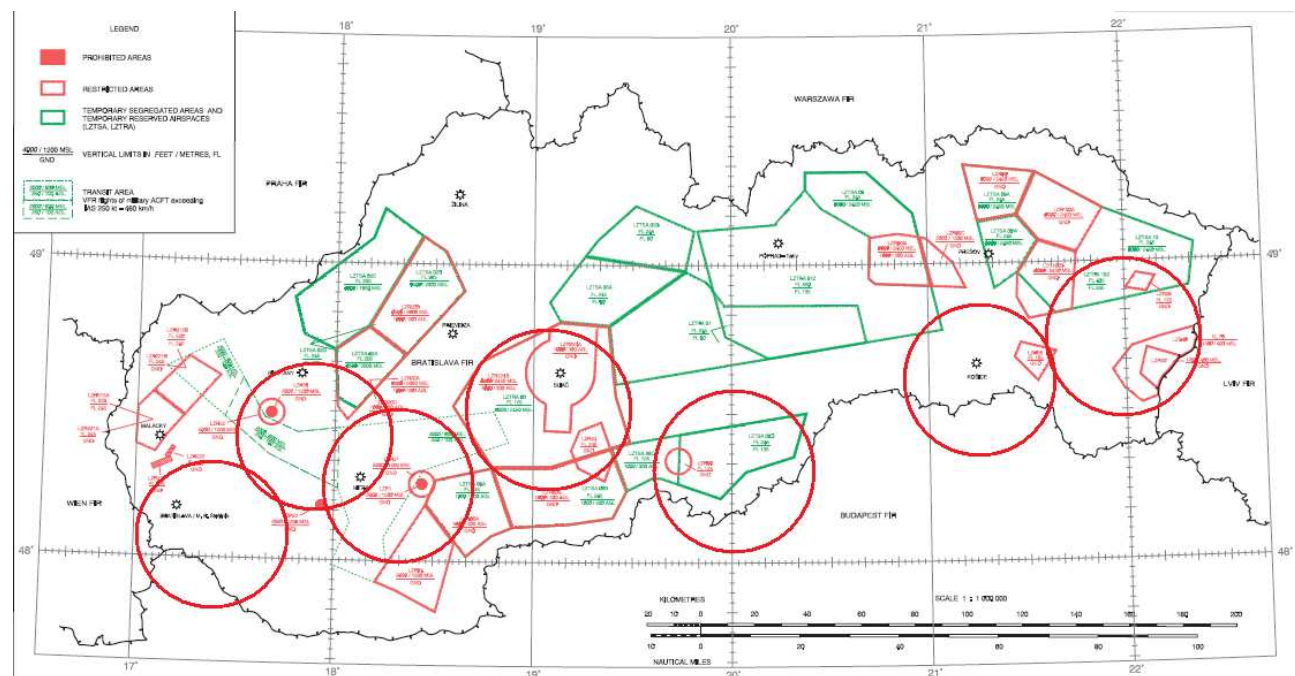

Fig. 7. Prohibited, Restricted, Temporary Segregated Areas in SR (source: Novak, 2009)

\section{Conclusion}

All radars are different (even if only due to the physical impacts of their operating locations) and creating a 'rule of thumb' for wind farm developments near all systems would require such a level of generalisation as to make it probably worthless.

Therefore, in considering the effect of wind turbines on radar, developers need to focus on individual radars in the vicinity of their planned development. It is important also that developers appreciate the nature and extent of any problem. (Novak, 2009) For example, studies into air defence radars that take no account of the associated Command and Control systems may be of very limited value.

Because both civil and military aviation communities have legitimate interests that must be protected; this includes protection against the adverse effects of wind turbines. However, there is scope for flexibility throughout the process of considering wind farm applications. 
The effects of wind turbines on the physical element of the air domain (as obstructions) are well understood and the procedures for handling them are relatively straightforward. Certainly, a flexible approach to sitting of turbines can be expected to pay dividends. Developers must, however, bear in mind that there are some locations in which the presence of turbines is unlikely ever to be tolerated.

The effects of wind turbines on electronic systems and the measures that can be taken to overcome these effects are less clear-cut. The sitting of wind turbines will, potentially, affect the radar sensors belonging to both civil and military users in much the same ways, although the operational impact of these effects will probably not be the same. As further research is conducted and experience with existing (and currently approved) wind farms grows, all stakeholders will be able to determine more precisely what may be acceptable and what will not. No matter what, however, this is an area in which early dialogue with the relevant stakeholders is particularly recommended.

\section{Acknowledgments}

This research has been supported by the Scientific Grant Agency of the Ministry of Education of Slovak Republic and the Slovak Academy of Sciences (VEGA No: 1/0274/08).

\section{References}

CAP 670, (2009), Air Traffic Services Safeguarding Policy, in CAA, CAA document http://www.caa.co.uk/docs/33/cap670.pdf

CAP 764, (2009), CAA Policy and Guidelines on Wind Turbines, in CAA, CAA document www.caa.co.uk/docs/33/Cap764.pdf

Gabriel, M \& Hill, W. (2004), Investigation of the impact of wind turbines on the MSSR installations at Dooncarton, QinetiQ Ireland, QinetiQ document http:/ / www.sei.ie/index.asp?locID=325\&docID =-1

Greving, G. (2001), Numerical Analysis of the Effects by Scattering from Objects on ATC Radar and Various Methods for its Reduction - Theory, EUROCONTROL, Paris

Knil, A. (2002), Potential Effects of Wind Turbines on Navigational Systems, CAA UK, London

Knil, A. (2001) Wind Turbines and Radar: Operational Experience and Mitigation Measures, CAA UK, London

Knott E. F., Shaeffer J. F. \& Tuley M. T. (1993), Radar Cross-Section, Artech House Inc., 1993, Second Edition, ISBN 0-89006-618-3 pp. 90-92.

Lewis, R. (2001) Information Paper - Radar Mitigations, CAA SRG, available from CAA SRG web page.

Novak, A. (2009), Wind farm impact on CNS interests, in 8th international technical systems degradation seminar - Liptovský Mikuláš, 15-18 April 2009, Lublin: WydawnictwoDrukarnia Liber Duo, ISBN 978-83-911726-5-0, pp. 126-131.

Novak, A. (2009), Wind farms and aviation, in Aviation, - ISSN 1648-7788, Vol. 13, no. 2 (2009), pp. 56-59.

Skolnik M.I. (1962), Introduction to Radar Systems, McGraw-Hill book company inc., pp. 4851. 


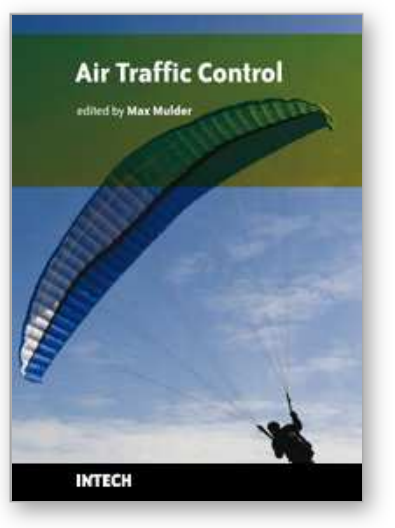

\author{
Air Traffic Control \\ Edited by Max Mulder
}

ISBN 978-953-307-103-9

Hard cover, 172 pages

Publisher Sciyo

Published online 17, August, 2010

Published in print edition August, 2010

Improving air traffic control and air traffic management is currently one of the top priorities of the global research and development agenda. Massive, multi-billion euro programs like SESAR (Single European Sky ATM Research) in Europe and NextGen (Next Generation Air Transportation System) in the United States are on their way to create an air transportation system that meets the demands of the future. Air traffic control is a multi-disciplinary field that attracts the attention of many researchers, ranging from pure mathematicians to human factors specialists, and even in the legal and financial domains the optimization and control of air transport is extensively studied. This book, by no means intended to be a basic, formal introduction to the field, for which other textbooks are available, includes nine chapters that demonstrate the multi-disciplinary character of the air traffic control domain.

\title{
How to reference
}

In order to correctly reference this scholarly work, feel free to copy and paste the following:

Andrej Novak (2010). ATM Systems and Wind Farms, Air Traffic Control, Max Mulder (Ed.), ISBN: 978-953307-103-9, InTech, Available from: http://www.intechopen.com/books/air-traffic-control/atm-systems-and-windfarms

\section{INTECH}

open science | open minds

\section{InTech Europe}

University Campus STeP Ri

Slavka Krautzeka 83/A

51000 Rijeka, Croatia

Phone: +385 (51) 770447

Fax: +385 (51) 686166

www.intechopen.com

\section{InTech China}

Unit 405, Office Block, Hotel Equatorial Shanghai

No.65, Yan An Road (West), Shanghai, 200040, China

中国上海市延安西路65号上海国际贵都大饭店办公楼 405 单元

Phone: +86-21-62489820

Fax: +86-21-62489821 
(C) 2010 The Author(s). Licensee IntechOpen. This chapter is distributed under the terms of the Creative Commons Attribution-NonCommercialShareAlike-3.0 License, which permits use, distribution and reproduction for non-commercial purposes, provided the original is properly cited and derivative works building on this content are distributed under the same license. 